\title{
Caring and daring discourses at work: doing gender through occupational choices in elderly care and police work
}

Andreas Fejes and Ulrika Haake

\section{Linköping University Post Print}

\section{Tweet}

N.B.: When citing this work, cite the original article.

The original publication is available at www.springerlink.com:

Andreas Fejes and Ulrika Haake, Caring and daring discourses at work: doing gender through occupational choices in elderly care and police work, 2013, Vocations and Learning, (6), 2, 281-295.

http://dx.doi.org/10.1007/s12186-013-9097-1

Copyright: Springer Verlag (Germany)

http://www.springerlink.com/?MUD=MP

Postprint available at: Linköping University Electronic Press

http://urn.kb.se/resolve?urn=urn:nbn:se:liu:diva-87121 
Caring and daring discourses at work: doing gender through occupational choices in elderly care and police work

Andreas Fejes and Ulrika Haake

Linköping University and Umeå University

Published in Vocations and Learning 2013, 6(2), 281-295.

\begin{abstract}
This paper aims to problematise how gender is being done -1 . through occupational choices in two occupations that are traditionally gender divided, elderly care and police work, and 2. through the division of work assignments in police work. Interviews with care workers and police officers are analysed using a "doing gender" perspective, a poststructural notion of subjectivity inspired by Michel Foucault and positioning theory. We argue that a caring discourse operates in elderly care workers' and police officers' statements concerning occupational choices, while a daring discourse operates in statements concerning occupational choices within police work. Through these discourses, gender is being done in different ways; caring dispositions are constructed as totally female within the context of elderly care but as more gender-neutral in police work. At the same time, a macho or daring attitude is constructed as a male attribute in police work. Such constructions may have social consequences in terms of dividing work tasks for police, where male officers work in more prestigious and "dangerous" areas, while female officers are left with less prestigious, more caring-associated working areas.
\end{abstract}

Key words: Doing gender, Foucault, Elderly care work, Police work, Occupational choice

\title{
Introduction
}

It has been argued that the reasons behind individuals' occupational choices are based on intrinsic and/or extrinsic reasons (cf. Fejes \& Nicoll, 2010), and such choices have been explained in the literature in three different ways by referring to rational decision-making (see overview made by Billett et al., 2010):, by referring to social structures and processes (cf. Simpson, 2005; Gottfredson \& Lapan, 1997) and by referring to personal values and life histories (cf. Billett et al., 2010). An important element in explaining occupational choices in relation to social structures is the argument that these choices are not gender neutral but intertwined with gendered societal traditions and expectations regarding abilities, skills and competencies for men and women. Gottfredson and Lapan (1997, p. 419) argue that 'perceptions of, and preferences for, gender roles are central to...occupational aspirations'. In contrast, as Bimrose (2001) argues, theories used for career guidance have assumed that men and women exhibit identical career behaviour. Such perceptions of roles and assumptions about career behaviour are connected to occupational stereotyping, that is, the way the labour market is divided into "neutral/gender mixed", "male" and "female" occupations; it also describes the way in which certain occupations are gender divided internally such that men and women work in different parts of an organisation or are given different tasks (Haake, 2011). 
Occupational stereotyping, for example, can be seen in elderly care work. As Somerville (2003) illustrates, many female care workers choose this occupation based on the convenience of location and availability of work rather than from an occupational preference, thus contributing to existing occupational stereotyping of elderly care work. Further, occupational choices are related to the ways work tasks within organisations are gender divided. Previous research has illustrated how police work is gender divided, where males work with for example serious crimes, search missions and SWAT teams and women with more administrative task and as in-house investigators or with child/family investigations and social assignments towards schools and the social services (De Guzman \& Frank, 2003; Garcia, 2005; Rabe-Hemp, 2009).

To avoid social determinism and encourage seeing people as free agents the literature on learning and careers has called for the development of a more situational and individuated understanding of how occupational choices are actually made and what motivates and directs individuals towards a certain career (Billett et al., 2010). Occupational choices are part of our learning careers and life histories, and learning is connected to 'identity and situation and cannot be extracted from them' (Bloomer \& Hodkinson, 2000, p. 595). Thus, it is argued that there is a need for a greater focus on individuals' learning careers, and how these are connected to wider social structures, to understand the how and why of occupational choices (cf. Hodkinson \& Sparkes, 1997; Bloomer \& Hodkinson, 2000; Billett et al., 2010).

The ways to view occupational choice described above do tell us something important about the how and why of those choices, although from different perspectives. Although many scholars acknowledge the importance of gender in relation to occupational choices, they generally do not direct any attention towards how those choices contribute to the doing of gender, i.e., rather than focusing on how gender is being done through choices, the focus has been on how those choices might be influenced by gender. Nor does the above-mentioned research take into account the ways in which discourses on occupational choices and work division within occupations are constructed by and construct subjectivities.

This article aims to contribute to the above debate by focusing on how gender is being done through discourses on occupational choices and work division in relation to two occupations that have historically been and remain gender divided: elderly care work (focus on occupational choices) and police work (focus on occupational choices and work division). By drawing on a doing gender perspective and a post-structural notion of subjectivity, we will be able to illustrate how people, by drawing on wider discursive resources, are positioned and position themselves as particular subjects. Such positioning, we will argue, is constructed by and constructs discourses that classify occupations and work tasks within occupations as male or female. The main contribution of the article is our description of how subjects are positioned and position themselves, and in doing so, we hope to open up a space for doing gender differently.

\section{A theorisation and questions of method}

To analyse how gender is done and how subjectivity is shaped, we draw on a doing 
gender perspective (Kelan, 2010; West \& Zimmerman, 1987, 2009), a post-structural notion of subjectivity inspired by the work of Michel Foucault (1988, 1998, 2007; Fejes \& Nicoll, 2008; Fejes \& Dahlstedt, 2013; Haake, 2009) and positioning theory (Davies \& Harré, 1990; Harré \& van Langenhove, 1999). The central concepts used here are doing gender, subjectivity, and positioning.

In the doing gender perspective, gender is not seen as something that is pre-defined or deterministic. Rather, gender is viewed as a verb, a practice, and something we do in social interaction (Shields \& Dicicco, 2011; West \& Zimmerman, 1987). Doing gender generally means creating differences between men and women, differences that are not natural, essential, or biological but rather socially and culturally constructed (Connell, 2008; Connell \& Messerschmidt, 2005; West \& Zimmerman, 1987; 2009). Societal and cultural ideas about gender are thus constructed and reproduced through societal and organisational cultures, structures and practices, e.g., through occupational choices and work divisions in organisations (Gherardi, 1995; Martin \& Collinson, 1999). Different behaviours and actions thus "do" gender in different lines of business, organisations and specific occupations. The basic assumption is that "doing gender" is a process through which the gender binary (man/woman) is enacted (Kelan, 2010). The doing gender perspective therefore seeks to understand the ways in which we talk and perform that uphold the gender binary and gendered expectations. The ways in which subjects conform to social expectations of appropriate behaviour for their socially perceived sex category is a matter of interest (Patterson, Mavin \& Turner, 2012).

With an understanding of how gender is done in specific contexts, we can begin to answer questions of how gender can be undone (made uninteresting) or re-done (filled with other and non-stereotypical gender attributes and behaviours) to de-essentialise gender (Butler, 2004; Jeanes, 2007; Kelan, 2010; Mavin \& Grandy, 2012; Morash \& Haarr, 2012; Patterson, Mavin \& Turner, 2012). Some studies argue that gender can be undone by women entering occupations that have been traditionally male dominated (see, for example, Kelan, 2010), while others conclude that this only creates an internally gender segregated work division such that women in the police force, for example, will be increasingly separated from "real” police work (Rabe-Hemp, 2009). Morash and Haarr (2012) have shown that lower ranking female officers in particular are more likely to essentialise gender differences and to describe themselves as doing traditional gender, while other officers associate themselves with a mixture of female stereotypic and nonstereotypic traits.

Through occupational choices and organisational work divisions, people are doing gender, shaping subjectivities, producing binaries between women and men and, in doing so, creating mechanisms for inclusion and exclusion in relation to occupations. These mechanisms may in turn have social consequences in terms of who enters an occupation, who feels satisfied in an occupation and who drops out of or leaves an occupation. From a doing gender perspective, the focus in this study is therefore directed at how the talk of occupational choices and work divisions produces gendered discourses and different positions for men and women within the studied occupations. To accomplish this, we first analyse the differences in the way men and women speak about their occupational 
choices and/or work divisions, and then we analyse how those ways of speaking are related to one of the sexes (male or female) regardless of who (man or woman) is speaking. Thus, in this study, the sex category is incorporated into our understanding of doing gender based on the idea that a binary divide constrains and restricts how men and women do gender (Mavin \& Grandy, 2012). However, this does not mean that gender binaries cannot be challenged or unsettled by means of undoing or re-doing gender (Kelan, 2010; Morash \& Haarr, 2012).

The doing gender perspective is combined with a post-structural perspective on subjectivity. With such a perspective (Foucault, 1998, 2007), there is no a priori self as an object or thing. The 'self' is decentred and analysed as it is shaped by language in specific ways. In this decentring, there is potential for the description of a multiplicity of subjectivities, and multiple and partial uptakes and elisions, but they may take specific forms through the regularities of description. What is produced is the effect of the powerknowledge constellations of the discourses available to be taken up in this way. We are positioned at any time by what our location in power-knowledge regimes allows us to say, and we describe ourselves in relation to what is discursively available to take up in that location. Subjectivities emerge through and within regularities of self-description. This is a productive and relational notion of power, where people are both the products and the producers of discourse. Taking the notion of subjectivity as being decentred and power as being relational and productive allows us to analyse how subjects emerge and are positioned through discourse. As Hollway (1984, p. 236) argues:

Discourses make available positions for subjects to take up. These positions are in relation to other people. Like the subject and the object of a sentence... [people are] placed in relation to each other through the meaning which a particular discourse makes available.

However, such notions do not provide the tools necessary to understand how people come to take up and produce discourse in the micro-context of work, i.e., how people engage with discourse. Inspired by positioning theory (cf. Davies \& Harré, 1990) and its focus on positioning as interaction, our analysis focuses on how people engage with and thus are positioned and position themselves through discourse. It is through such engagement that people come to know who they are. Here, while positioning theory (e.g., Harré \& van Langenhove, 1999; Hollway, 1984) mainly focuses on the interaction between people in conversation, our focus is on how people, through statements in interviews, draw on discursive resources and, through this, are positioned and position themselves as subjects.

Empirically, this article draws on two research projects that focused on elderly care and police officers, respectively. Both studies had an interest in how people came to enter their specific occupations. These two occupations have been historically (and remain) gender divided and thus serves as good starting points for problematising how gender is being done. Elderly care work is mostly performed by women, while police work is dominated by men (Stewart, 2008), although the number of female police officers has increased in many countries, including Sweden, for example, in recent years. 
Furthermore, both occupations are similar in so far as caring relations are important. In elderly care work, the main caring relationship is between the care worker and the elderly person, while the main caring relationship for the police officer is with crime victims and the offenders.

Drawing on the above-mentioned post-structural theorisation, our focus is analysing how gender is being done discursively through positioning by analysing interview transcripts from the two research projects. In the first study, fifteen semi-structured interviews were carried out (Kvale, 1996) with twenty-three care workers in a medium-sized city in the south of Sweden. All interviewees were females as no male workers were available for interview at the research site. This also provides an approximate representation of the gender balance of many elderly care worksites. Elderly care work is almost exclusively a female occupation in Sweden, as it is elsewhere, and there is no clear work division in its organisation; all care workers perform similar work tasks. Eleven interviews were individual, and four were group interviews conducted with two to five interviewees together. The reason for conducting group interviews was practical: to speak with as many participants as possible within a time schedule that had to be adapted to their work and studies (Vaughn et al., 1996). The interviews were conducted in Swedish, transcribed in full and translated by one of the authors. Questions were posed about the reasons why the care workers entered elderly care as an occupation as well as their educational attainment and their participation in in-service training.

In the second study, 28 interviews were conducted with police officers or lower and middle managers in the police in northern Sweden. All interviewees were sworn police officers. Eighteen of the interviewees were men, and ten were women; 23 interviews were conducted face-to-face, and five were conducted over the telephone. All interviews were recorded and fully transcribed and then translated by one of the authors. Questions were posed about why the interviewees had become police officers and about their career paths as well as their thoughts about gender in relation to the different working areas in the police force. Police work in Sweden, as elsewhere, is gender divided and maledominated, although the differences are decreasing. There are clear divisions of labour within police organisations that concern many different tasks, which makes it interesting to see how gender is being done through internal work division.

In the following analysis, we have drawn on the theorisation described above and focus analytically on the ways elderly care workers and police officers are positioned and position themselves as subjects in terms of gender in relation to the discourses available to them. Gender is done through positioning by drawing on discursive resources. When reading the interview transcripts, we asked the following question: How do the care workers and police officers position themselves and how are they positioned in terms of gender? The analysis identifies two discourses drawn upon and supported by means of the interview transcripts: a caring discourse and a daring discourse. Both discourses focus on how gender is being done through occupational choices, while the latter discourse also focuses on how gender is being done through organisational work division within the police force. 


\section{A caring discourse}

In the following section, we will focus on how caring relations in both elderly care work and police work are constructed in our interview transcripts and how gender is being done through this.

Elderly care

There are two ideas that elderly care workers draw upon in relation to their occupational choice. They position themselves as having caring dispositions, and they position themselves as doing good work for others for intrinsic rather than extrinsic reasons. Working in elderly care is spoken of as something one does based on experiences of being a mother or daughter:

It was because my mother had MS and she lived in an elderly care home, and my dad. So, this might be the reason why I applied. (Jasmine)

Here, the care worker refers to her experiences of being a daughter who takes care of her mother and father. Another reason for working in elderly care provided by a different care worker is her experiences of being a mother:

I've been working within care work for seventeen years. Previously, I worked in a store, and then I changed occupation for personal reasons. It was for my children's sake as it [working in the store] was evening work. (Anna)

Here, care work is an occupational choice construed as enabling the woman to be flexible and thus be home to care for her children in the evenings.

In both these quotations, the elderly care worker is constructed as someone with a caring disposition. As a mother and daughter, one cares for relatives, a vocation that is then extended to caring for the elderly. There is a conflation of private and occupational life, and a caring self is constituted (Skeggs, 1997). '[T]he caring subject is constructed by the conflation of caring for with caring about, in which the practices of caring become inseparable from personal dispositions' (Skeggs, 1997, 56). Caring for signifies the actual tasks of caring, whilst caring about signifies the social dispositions and a relation between the one who cares and the one who is cared for. In this case, the caring about and caring for family members is extended into the workplace, which in turn is then extended back into family life; i.e., being a mother is constructed as providing a disposition conducive to caring for the elderly at the same time as such care provides the flexibility to care for the children.

The above analysis shows that the discourse on care seems to be gendered. The way it is constructed resonates quite well with the way caring was described by Florence Nightingale (1969). According to her, all women have experiences of caring, and thus, they can be nurses. Nightingale argued that one should not engage in discussions about whether nursing is a female or male task but rather simply abide by the calling and do one's best. Similarly, in this study, these female caregivers described caring for family as their experience. However, in their descriptions, becoming a care worker requires specific 
dispositions of care - not everyone is suitable. This is illustrated in the following exchange between four care workers, where care is something constructed as inherited; some are suited, others not.

Interviewer: And how would you express it as it seems as if you do a lot of different things? How do you learn this job?

\section{Sofie: Experience}

Katherine: Yes, and to work.

Louise: In my opinion, intuition.

Katherine: Yes, some are better suited and some are not suited for this job. That's the way it is. You need to be able to keep a lot of things in your mind during the day. To know what to do.

Sofie: Yes, above all, one needs to be interested in working with people. Otherwise, you have no business being here.

Katherine: Yes, one has to.

It's the wrong attitude to come here just to earn money and to have a job. Instead, one really needs to like working with people. (Sofie)

And then one needs to think that it could have been my Mum or Dad who lived here. (Denise)

Here, the disposition of care work emerges through an experience of care that is already gendered. At the same time, elderly care work is described as something you should not be doing for the money. Instead, there is some kind of higher calling, where the occupational choice should be made for intrinsic rather than extrinsic reasons. Care is for the elderly and their relatives. It is important to have the 'right attitude' for this kind of work, meaning that one should do this work because one 'really needs to like working with people'. This is further accentuated in the following quotations from two of the care workers:

And I agree with what was previously said by one of my colleagues, we are not here only for the salary. We are here to help people. And this is how we need to... if they were not here, we wouldn't be here. And it is also something else, and thankfully we are taking care of them. So this is... it is worthwhile. Relatives of the elderly people don't understand the effort we are making. (Christine)

With the salary we get, one could say that we are not doing this job for the money. No we aren't. It’s because one enjoys the job. Absolutely. (Alexia) 
What we see here is how care work is constructed as something one should do for the elderly and something one should enjoy. Being a care worker is not about doing it for the money; instead, there is a higher calling and a 'right attitude'. This reasoning draws on and constructs a gendered discourse of care. Here, caring dispositions are positioned as those that are female and those that can be used in both private and occupational life. They talk about unpaid care work in the home, which is transferred to the world of work. Speaking of care work for the sake of money is construed as something ugly and wrong.

\section{Police officers}

To further analyse how gender is being done through a discourse on care, we turn to interviews with police officers. Here, a discourse on care is mobilised by both female and male officers. However, it is mobilised slightly differently here compared with the narratives of the elderly care workers. On the one hand, there are regularities in descriptions about liking to work with and help people that, among the police officers, are connected to a 'sense of justice' rather than 'not doing it for the money'. On the other hand, there are some police officers, most often male, who position their occupational choice in conflict with a discourse on care.

Initially, several of the police officers state that they like working with people. For example, consider Simon, who 'wanted to work with people,' and Brad, who 'likes to work with people'. There are regularities to these descriptions in our interview transcripts. Some officers even state that they are suitable for such work because they are empathetic and thus good at relating to people. Such descriptions are related to a strong sense of justice and ideas about helping people, putting things in order, making a difference and having caring dispositions, which is visible in the following quotations from interviews with Laura, Karen, Carol and Alvin:

But I have never regretted making this occupational choice. And one has always had these dreams about helping people, putting things in order and being there for others. Typically female, and that's how it ended up, and then things have moved along. (Laura)

To make a difference in society, to change and make things better, to make a difference really. And that's what motivated me, and I like working with people, and I like this job that varies. (Karen)

I found it interesting to work with people, somehow to make a difference. (Carol)

This was probably a job where you could help, protect and correct things a bit, to feel that you contribute, make a difference to others, short and very simple, and no great heroic parts, but only something that would feel good. (Alvin)

These descriptions draw on and construct a caring discourse where liking to work with people and a sense of justice are intertwined and there is a higher calling for care. 
Working as a police officer makes you 'feel good'. However, gender is being done in a somewhat different way among the police officers than among the care workers. Both female and male police officers are positioning themselves as having caring dispositions, similar to the care workers. Working as a police officer is about helping and protecting people. At the same time, many of the police officers are positioning themselves as caring out of a sense of justice in terms of bettering society. Such positioning of work, where care is connected to a sense of justice, makes possible a more gender-neutral concept of care that allows for both men and women to be caring and to have caring dispositions. The caring discourse is thereby gendered in a different way than in elderly care work, and it could be argued that gender is re-done within the caring discourse in police work (Kelan, 2010; Morash \& Haarr, 2012).

However, not all police officers assume a position that includes a caring disposition, nor do they all construct themselves as having the same kind of sense of justice. For example, according to Peter, his occupational choice 'was not a calling or any such thing'. Similarly, as Steven explains:

I wanted to be where things happened. I had no illusions about saving lives or helping people to get a better life, I like to be where things happen. And then I'm a quite empathetic person, I believe, so I have that part, that's the foundation of it all. (Steven)

Being empathetic is here constructed as a fact, as a foundation to police work and as something Steven is. At the same time, Steven describes his occupational choice as a way to be 'where things happen' and says he had 'no illusions about saving lives'. Thus, police work is not something he does primarily out of a concern for others. This is quite interesting, as it positions him, if not in direct opposition to, then at least somewhat apart from his colleagues who mobilise a caring discourse.

Further, if elderly care workers clearly position themselves as not working for the money but rather for some higher good, it seems to be possible for some of the male police officers to explicitly draw on extrinsic motivations for their occupational choice. For example, as Thomas explains, the police academy was a way of supporting himself and letting time pass:

You had a salary during the entire educational programme, so it didn't cost anything, so I could jump on the train and wait until I had decided what I wanted to do....And this was a way of passing the time. (Thomas)

Here, there is no mobilisation of caring dispositions. Police work is constructed as an option for supporting oneself rather than something chosen out of a concern for others. It is interesting to note that in the interview transcripts, and as illustrated in the two examples above, it is only male officers who position themselves without any connection to a caring discourse, although the caring discourse for police work is, as illustrated above, constructed in a way that allows both females and males to draw upon it. 
We can conclude that the caring discourse is both similarly and differently constructed through the occupational choices made by care workers and police officers. What is similar is the way both care workers and police officers position themselves as people who have caring dispositions and who chose their work to help other people. In the case of the care workers, care is for the elderly and their relatives and should not be motivated by a desire for financial gain but rather because of some kind of higher calling. For the police officers, caring for perpetrators and crime victims is constructed as stemming from a sense of justice and the desire for the betterment of society. Because these constructions are made by both female and male police officers, gender through a caring discourse is done differently within the two occupations. However, a few male police officers position themselves in opposition to a caring discourse.

So far, the analysis indicates that a caring discourse is gendered and that caring dispositions are constructed as something female within elderly care work, which is in line with prior research (cf. Fejes \& Nicoll, 2010; Skeggs, 1997; Waerness, 1996). At the same time, we have illustrated how gender is re-done within police work, allowing both women and men to position themselves as caring.

\section{A daring discourse}

In this section, we will focus on how gender within police work is being done more clearly through a daring discourse. In what follows, we will identify both male and female police officer positions that do gender by focusing on statements about occupational choices and through statements that gender-label tasks in police work.

The daring discourse consists of men's talk of choosing the career path of a police officer because of the job's thrilling aspects. Female police officers are excluded from positions in the daring discourse, and both men's and women's statements focus on the daring parts of police work as something male and on women as being excluded from this. In the daring discourse, police work is described as being exciting, chasing crooks and getting high-level kicks:

There was this gang in Stockholm that smuggled heroin and other stuff... that got me to say 'shit, this I want to do - I want to chase the drugs'. (Aron)

The daring discourse is also about boys' special interests and young boys' dreams of an exciting career. Many of the descriptions begin in the primary school years, when children are asked about their dream careers for the first time. Some say that they had dreamed of being a police officer for as long as they could remember and think that almost every (boy) has had this dream at some point. In this study, it is only men who talk about the police officer's career as a daring boy's dream. These men often refer to this dream as the dream of boys and not as a gender-neutral dream or a girl's dream. Gender is thus done through the talk of occupational choice (Connell, 2008; Connell \& Messerschmidt, 2005; Deutsch, 2007; West \& Zimmerman, 1987; 2009). The boy's dream is exemplified in the statements by the following two police officers, both male: 
As it said in the recruitment brochure, it [the work as police] is exciting and diversified. Then there was a helicopter and a boat and some other stuff that could arouse a young boy's interests. (Lucas)

I had a boy's dream... and in third grade I wrote an essay... about wanting to become a police officer. And the teacher read this essay to the whole school class and then he laughed and said that I didn't have the right resources for that. (Michael)

Here, police work 'arouses a young boy's interest', and it is a 'boy's dream' to work as a police officer. These statements position police work as something male, and through such statements, gender is being done; i.e., a dualism between male and female is constructed in relation to this specific occupation. If the statements had used phrases such as 'arouse a young child's interest' or 'it is a child's dream', gender might have been done differently.

Such dualism is further mobilised through interview statements where gender-labelled work areas are constructed in police work. Women are spoken of as working with administration, as in-house investigators, with child and family investigations, and with social assignments involving schools and the social services, while men are spoken of as working to fight crime, with search missions, with narcotics and serious crimes, in SWAT teams and technical units and in management positions. This phenomenon is problematised in earlier research in Sweden (Cedermark Hedberg, 1985; Dahlgren, 2007; Westin \& Nilsson, 2009; Åberg, 2001) as well as in other countries (De Guzman \& Frank, 2003; Garcia, 2005). Examples of how such work labelling is done can be seen in the following statements by two male officers and one female officer:

Yes, it has got to the point where... sex crimes, and these real relationship dramas, they tend to have become women's work. That's how it is. It's a pity, it's not good. (Aron)

Mainly, if you look at family-related violence, children issues, this is very typical female... So the women investigate, and the men are out on reconnaissance missions and... work with technical things. (Harry)

It may well be that women are more often assigned social tasks. Crime coordinators, child investigators, domestic violence, that we [women] are getting niche positions in a way there. (...) First, because no one else wants to have these tasks ... but then it's also a fairly comfortable life, avoiding being out there in the fighting areas... (Katie)

Such statements support the daring discourse and ideas of police work as a daring mission, at least for men. Although one of the officers quoted above argues that such a division of labour is "a pity", the statements, by dividing work areas in terms of gender, do gender and produce gendered subject positions. This is further supported in the following statement from a female police officer recruited to a unit for serious crimes and 
narcotics:

When I came there my chief said 'Amanda, we've never had any woman here before, I've never worked with any girl. How do you think this will work out?' I said 'It's cool, I've never worked with any girl either'. (Amanda)

Recurring statements from the interviews concerning the gender-divided tasks in the police organisation claim that women and men are good at different things, that it is a natural division of work, that women and men choose work areas due to different interests and that the "female" areas are lower status, which makes it difficult to recruit men there. The division of work into high and low status areas is also described in the following statement.

The largest "women's trap" we have here, in my opinion, it is to become an investigator and to be child and domestic violence investigators. It is very, very convenient to recruit women as investigators. Then, you put them in a room, they go nowhere career-wise... then you get no other experience, what do you do then? Then they [the women] sit there nicely in their room and deliver investigation after investigation after investigation for the rest of their lives and don't bother anyone. (...) It's such a fucking “woman trap”, and all the time they call for women's empathy, 'you are so good at this', and yes, it's really easy for a woman to take on these cases. (Susan)

The above statement illustrates how positioning is taking place, where tasks seen as female are positioned with a lower status compared to the "male" tasks. Females are offered certain positions, and as a result, certain tasks and dispositions are essentialised as female. They are offered and then taken up by female police officers, thus reinforcing the discourse. By taking up such positions, gender differences are reproduced and done by both male and female officers. A gendered division of work is further construed by referring to gender specific traits.

I think the drug unit, when talking about serious crimes, is typically male. (...) It's the same with the SWAT teams. Crime fighting units have far more men. (...) I think it has to do with what is seen as macho. It is an old tradition that one should be a real man out there. It is believed that a woman is a small, sweet, caring person... (Amanda)

Being macho is constructed as a male trait and something related to certain work areas within the police force, while the female is 'the small, sweet, caring person'. Here, women are put in opposition to the daring discourse. Through this, the division of labour is constructed as something natural and unquestionable. By both male and female officers taking up the positions offered, gender differences are sustained and reinforced.

What we have illustrated in this section is how the daring discourse, as it operates in relation to occupational choice and the internal division of labour, is doing gender in a way that produces gender roles and what are seen as female and male traits. Men are 
constructed as being strongly attached to the daring (macho) discourse, while women are constructed as only being able to do inter-personal (caring) work, limiting women to assuming positions within the caring discourse, while men may assume positions within the caring and daring discourse. Women who are part of more daring units are constructed as people who do not fit the norm, which is in line with arguments put forth in previous studies (see, for example, Frewin \& Tuffin, 1998; Myers, Forest \& Miller, 2004).

\section{Discussion}

In this article, rather than focusing on how gender might influence occupational choices (cf. Simpson, 2005; Gotttfredson \& Lapan, 1997), we have focused on how gender is being done through occupational choices (cf. Gherardi, 1995; Martin \& Collinson, 1999) within elderly care work and police work and how gender is further done through statements about work division within police work. We have provided descriptions of how a caring discourse operates within both occupations, how a daring discourse operates within police work, and how gender is being done through these discourses. In care work, caring dispositions are constructed as female, where there is a conflation of caring for and caring about. Care in private life extends to occupational life and back again. Furthermore, care work should be carried out for intrinsic rather than extrinsic reasons, such as the desire for compensation. In police work, caring dispositions are constructed as having both female and male characteristics because care is connected to a sense of justice, thereby differing from care work and opening up a re-doing of gender. However, a caring discourse is challenged through statements from a subset of male police officers. In those statements, police work is not constructed as a calling; rather, the police academy was a way to get paid for being a student and to pass the time, or it was about being where things happen. Gender is further being done within police work through a daring discourse. The occupational choice to work as a daring police officer is constructed as something male: it is a boy's dream that arouses a young boy's interest. Furthermore, a daring discourse provides language that makes it possible to construct some tasks as female and others as male. Men do the macho work while females carry out the soft and inter-personal tasks.

Our analysis has illustrated how discourse makes a certain type of language available for use through which the positioning of subjectivities takes place; thus, gender is being done. A dualism between male and female is mobilised where certain dispositions and traits are connected to a certain gender. This is done through statements from both males and females. Positions offered are taken up, and through this, discourse is produced and reproduced. This can be seen in both occupations studied. In elderly care work, we only had access to female employees, and thus, our results about caring dispositions being constructed as female in that occupation may not be surprising. However, turning to police work, which is and has always been a male-dominated work area, the results are more interesting. In recent years, there has been an increase in females in police work, and our interviewees included both males and females. As the analysis indicates, the caring discourse is gendered differently in police work than in care work. In police work, the caring discourse allows for both men and women to take up a caring position, where care is related to a sense of justice rather than being related to caring practices outside of 
work (e.g., a mother caring for her children). However, at the same time, the daring discourse is gendering police work differently by labelling daring work tasks as male and caring work tasks as female, thus excluding women from the daring work tasks (see also Cedermark Hedberg, 1985; Dahlgren, 2007; De Guzman \& Frank, 2003; Garcia, 2005; Westin \& Nilsson, 2009; Åberg, 2001). Female police officers are therefore restricted to positioning themselves as caring, while male police officers can position themselves as either caring or daring or both caring and daring.

The discursive production of the essentialised view of women as having caring dispositions, as illustrated in our own analysis and further supported by previous research (see, for example, Bimrose, 2001; Gottfredson \& Lapan, 1995; Somerville, 2003; Stewart, 2008; Waerness, 1996), could suggest that men are less suitable for caring for our society's elderly or as less suitable for inter-personal work tasks in the police force. At the same time, the daring discourse of police work constructs men as having the disposition to be brave, unafraid, strong and thrill-seeking, thus further dividing genderbased tasks within the police. Thus, the way gender is being done in these two occupations may have social consequences in terms of who is working in what occupation and with what tasks, who is working in status-areas, who has the best chance of making a career and who feels good about the work they do (see, for example, Bloomer \& Hodkinson, 2000; Hodkinson \& Sparkes, 1997). However, these assumptions of differences between men and women need to be problematised and de-essentialised to further undo or re-do gender (Butler, 2004; Jeanes, 2007; Kelan, 2010; Mavin \& Grandy, 2012; Morash \& Haarr, 2012; Patterson, Mavin \& Turner, 2012) in their occupational choices and the division of work within different occupations. By focusing on how gender is being done through occupational choices, we have been able to provide descriptions about how both female and male police officers position themselves as having caring dispositions, and such descriptions, when read and related to different practices, may contribute to the further work of re-doing or undoing gender both in police work and, more widely, in other fields of work.

\section{References}

Billett, S., Newton, J., \& Ockerby, C.H. (2010) Socio-personal premises for selecting and securing an occupation as vocation. Studies in the education of adults, 42(1), 47-62.

Bimrose, J. (2001) Girls and women: Challenges for careers guidance practice. British Journal of Guidance \& Counselling, 29(1), 79-94.

Bloomer, M., \& Hodkinson, P. (2000) Learning careers: Continuity and change in young people's dispositions to learning. British Educational Research Journal, 26(5), 583597.

Butler, J. (2004). Undoing gender. London: Routledge.

Cedermark Hedberg, G. (1985). Kvinnor och män i polisutbildningen. Polissystemets reaktioner på en ökad andel kvinnor i polisyrket. [Doktorsavhandling] Stockholms universitet.

Connell, R.W. (2008). Maskuliniteter. Göteborg: Bokförlaget Daidalos AB.

Connell, R.W., \& Messerschmidt, J. (2005). Hegemonic masculinity: Rethinking the concept. Gender \& Society, 19, 829-859. 
Dahlgren, J. (2007). Kvinnor i polistjänst. Föreningen kamraterna, svenska polisförbundet och kvinnors inträde i polisyrket 1957-1971 [Doktorsavhandling] Umeå Universitet.

Davies, B. \& Harré, R. (1990) Positioning: The discursive production of selves. Journal for the Theory of Social Behavior, 20(1), 43-63.

De Guzman, M.C., \& Frank, J. (2003). Policewomen and their problems: the Philippine context. Policing: An International Journal of Police Strategies \& Management, 27(3), 396-412.

Deutsch, F. (2007). Undoing gender. Gender and Society, 21, 106-127.

Fejes, A. \& Dahlstedt, M. (2013) The confessing society: Foucault, confession and practices of lifelong learning. London: Routledge.

Fejes, A. \& Nicoll, K. (2010) A vocational calling: Exploring a caring technology in elderly care. Pedagogy, Culture \& Society, 18(3), 353-370.

Fejes A. \& Nicoll, K. (eds.) (2008). Foucault and Lifelong Learning: Governing the Subject. London: Routledge.

Frewin, K., \& Tuffin, K. (1998). Police status, conformity and internal pressure: A discursive analysis of police culture. Discourse Society, 9(2), 173-185.

Foucault, M. (1988). Technologies of the self. In L. Martin, H. Gutman \& P. Jutton (eds.), Technologies of the Self: A Seminar with Michel Foucault. Amherst: University of Massachusetts Press, 16-49.

Foucault, M. (1998). The Will to Knowledge: The History of Sexuality: 1. London: Penguin Books.

Foucault, M. (2007). Security, Territory, Population: Lectures at the Collège de France 1977-1978. Houndmills: Palgrave MacMillan.

Garcia, V. (2005). Constructing the 'other' within police culture: an analysis of a deviant unit within the police organization. Police Practice and Research, 6(1), 65-80.

Gherardi, S. (1995). Gender, Symbolism and Organisational Cultures. London, UK: Sage Publications, Ltd.

Gottfredson, L.S., \& Lapan, R.T. (1997) Assessing gender-based circumscription of occupational aspirations. Journal of career assessment, 5(4), 419-441.

Haake, U. (2009). Doing Leadership in Higher Education: The Gendering Process of Leader Identity Development. Tertiary Education and Management, 15(4), 291-304.

Haake, U. (2011). Att göra kön i ledarskap. En studie av ledarskap i vardag och kris inom Polisen. Umeå universitet: Pedagogiska institutionen, rapport nr. 87.

Harré, R. \& van Langenhove, L. (eds.) (1999) Positioning Theory. Oxford: Blackwell Publishers.

Hodkinson, P., \& Sparkes, A.W. (1997) Careership: a sociological theory of career decision making. British Journal of Sociology of Education, 18(1), 29-44.

Hollway, W. (1984) Gender difference and the production of subjectivity. In J. Henriques, W. Hollway, C. Urwin, L. Venn and V. Walkerdine (eds.), Changing the Subject: Psychology, Social Regulation and Subjectivity. London: Methuen, 227-263.

Jeanes, E. L. (2007). The doing and undoing of gender: The importance of being a credible victim. Gender, Work and Organization, 14(6), 552-571.

Kelan, E. (2010). Gender logic and (un)doing gender at work. Gender, Work and Organization, 17(2), 174-194 
Kvale, S. (1996). Interviews: An Introduction to Qualitative Research Interviewing. Thousand Oaks, CA: SAGE Publications.

Martin, P.Y., \& Collinson, D.L. (1999). Gender and sexuality in organisations. In M.M. Ferree, J. Lorber \& B.B. Hess (Eds.), Revisioning gender (pp. 285-310). London, UK: Sage Publications, Ltd.

Mavin, S., \& Grandy, G. (2012). Doing gender well and differently in management. Gender in Mangement: An International Journal, 27(4), 218-231.

Morash, M., \& Haarr, R.N. (2012). Doing, redoing, and undoing gender: Variation in gender identities of women working as police officers. Feminist Criminology, 7(1), 323.

Myers, K., Forest, K., \& Miller, S. (2004). Officer Friendly and the tough cop: Gays and lesbians navigate homophobia and policing. Journal of Homosexuality, 47(1), 17-37.

Nightingale, F. 1969. Notes on Nursing: What it is, and what it is not. New York: Dover Publications, INC.

Patterson, N., Mavin, S., \& Turner, J. (2012). Unsettling the gender binary: Experiences of gender in entrepreneurial leadership and implications for HRD. European Journal of Training and Development, 36(7), 687-711.

Rabe-Hemp, C. (2009). POLICEwomen or policeWOMEN?: Doing gender and police work. Feminist Criminology, 4, 114-129.

Shields, S.A., \& Dicicco, E.C. (2011). The social psychology of sex and gender: From gender differences to doing gender. Psychology of Women Quarterly, 35, 491-499.

Simpson, R. (2005). Men in non-traditional occupations: Career entry, career orientation and experience of role strain. Gender, work and organization, 12(4), 363-380.

Skeggs, B. 1997. The formation of class and gender. London: Sage publications.

Somerville, M. (2003). Who learns?: Enriching learning cultures in aged care workplaces. Paper presented at the 11th Annual International conference on Postcompulsory Education and Training: Enriching learning cultures, Gold Coast.

Stewart, B. (2008) 'Pathways into Policing: A Gendered Experience?', in The Proceedings of The Australian Sociological Association (TASA) Annual Conference, Melbourne, Australia.

Vaughn, S., J. Shay Schumm \& J. Sinagub. (1996) Focus Group Interviews in Education and Psychology. Thousand Oaks, CA: SAGE Publications.

Waerness, K. (1996). The rationality of caring. In S. Gordon, P. Benner \& N. Noddings (eds.), Caregiving: Readings in Knowledge, Practice, Ethics and Politics. Philadelphia: University of Pennsylvania press, 231-255.

West, C., \& Zimmerman, D. (1987). Doing gender. Gender \& Society, 1(2), 125-151.

West, C., \& Zimmerman, D. (2009). Accounting for doing gender. Gender \& Society, 23(1), 112-122.

Westin, C., \& Nilsson, A. (2009). Attityd- och bemötandeproblem inom polisen. Rapport till Rikspolisstyrelsen. Stockholm.

Åberg, B. (2001). Samarbete på könsblandade arbetsplatser - En könsteoretisk analys av arbetsdelning mellan kvinnor och män i två yrken: akutsjuksköterskor och ordningspoliser. [Doktorsavhandling] Örebro universitet. 